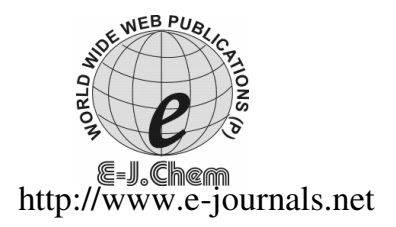

ISSN: 0973-4945; CODEN ECJHAO

E-Journal of Chemistry

2012, 9(1), 99-106

\title{
Production of Oleic Acid Based Wax Ester Using Acidic Homogeneous Catalysts
}

\author{
NAOWARA AL-ARAFI and JUMAT SALIMON* \\ School of Chemical Sciences and Food Technology \\ Faculty of Science and Technology, Universiti Kebangsaan Malaysia \\ 43600 Bangi, Selangor, Malaysia \\ jumat@ukm.my
}

Received 24 May 2011; Accepted 31 July 2011

\begin{abstract}
Four homogeneous acidic catalysts were tested for their ability to catalyze the esterification reaction of oleic acid and oleyl alcohol to produce oleyl oleate, a wax ester. Sulfuric acid showed relatively higher specific activity. Various reaction parameters were optimised to obtain high percentage yield of oleyl oleate. The optimum condition to produce oeyl oleate was reaction time; $5 \mathrm{~h}$, temperture; $90^{\circ} \mathrm{C}$, amount of sulforic acid $0.15 \mathrm{~g}$ and molar ratio of oleyl alcohol to oleic acid; 1:1. Percentage yield of wax ester obtained at these optimum reaction conditions was 93.88. Disappearance of carboxylic acid $(\mathrm{C}=\mathrm{O})$ peak has confirmed by FTIR with appearance of ester $(C=O)$ peak at $1739 \mathrm{~cm}^{-1}$. ${ }^{1} \mathrm{H}$ NMR spectra analyses confirmed the result of oleyl oleate with appearance of ester (- $\left.\mathrm{CH}_{2} \mathrm{OCOR}\right)$ at $4.02 \mathrm{ppm}$ and also the ${ }^{13} \mathrm{C}-\mathrm{NMR}$ confirmed the result with appearance of ester $(\mathrm{C}=\mathrm{O})$ peak at $173.2 \mathrm{ppm}$. The low-temperture behavior of compound synthesized was determined through its pour point (PP), viscosity index (VI) and flash point (FP) values. The results showed that oleyl oleate exhibited the most favorable low-temperture performance of PP, VI and FP with $-31{ }^{\circ} \mathrm{C}, 197.5$ and $320{ }^{\circ} \mathrm{C}$ respectively. This is due to increase of the molacular weight thus improve the low temperture property significantly.
\end{abstract}

Keywords: Wax ester, Oleic acid, Oleyl alcohol, Homogeneous catalyst, Esterification reaction

\section{Introduction}

Wax ester are an important class of fine organics that are widely used in cosmetic, pharmaceutical and lubricant industries ${ }^{1}$. Special characteristics of non-toxicity, good fat soluble properties and excellent wetting behaviour at interfaces make them very special to be used in cosmetic formulations (cleansers, conditioners and moisturizers) ${ }^{2}$. Natural wax ester can be extracted from animals and plant materials such as beeswax, sperm whale and jojoba oil. However, they are often in short supply and at present too expensive for commerical exploitation ${ }^{3,4}$. 
Wax esters are long chain esters that are derived from fatty acids and alcohols with chain lengths of 12 carbons or more ${ }^{5}$. Currently, most of the wax esters used commercially are of synthetic origin. They are generally produced by esterification reaction of an alcohol with an organic acid in the presence of an acid catalyst ${ }^{6}$. In order to start the esterification reaction, a proton transfer from acid catalyst to the alcohol and forms an alkyloxonium ion. Acid is protonated on its carbonyl oxygen. Nucleophilic addition of a molecule of the alcohol to carbonyl carbon of acid forms an intermediate product. This intermediate product loses a water molecule and proton to give an ester ${ }^{7-11}$.

Esterification reaction can be realized in the absence of catalysts, it is extremely slow, because of autoprotolysis of the carboxylic acid. Catalysts such as mineral acid, $p$-toluen sulphonic acid and ion exchange resins are always used in liquid phase esterification reactions to raise the product yield ${ }^{12-14}$. Since the naturally occuring wax esters are expensive and limited in access, the need to synthesize the compound has grown. There are many published papers using enzimatic catalysts to prepare oleyl oleate (wax ester). However there are no reported work using acid homogeneous catalyst for oley oleat synthesis.

Wax ester are usually harder, less greasy and more brittle than fats. The compounds have many potential applications due to their excellent wetting behavior at interfaces and a non-greasy feeling when applied on skin surfaces. Wax ester is also superior lubricant in high-speed machinery, work tools and metal cutters because it promotes extension of the life of all moving parts. Other examples of the commercial application of waxes are in detergent and polish used for the cleaning and protection of surfaces ${ }^{15}$. The physical properties of wax esters are very important from lubricant formulator point of view. Therefore the physical properties such as melting point, viscosity, specific gravity and reflective index were measured for pure wax ester. For example the melting points of long-chain wax esters (e.g. oleyl palmitate, oleyl oleate) are below $0{ }^{\circ} \mathrm{C}$ while the boiling points are up to $300^{\circ} \mathrm{C}^{16}$.

The objective of this study was to synthesis wax ester by esterification reaction of oleic acid using homogeneous acid catalyst. Optimization the reaction with several vcariables that affect the yield such as molar ratio of oleic acid to oleyl alcohol, amount of catalyst, reaction time and reaction temperature have been done.

\section{Experimental}

Oleic acid (90\%) and oley alcohol (85\%) were purchased from Aldrich chemical company (Germany). Ethyl acetate, ethanol, sodium hydroxide, sodium hydrogen carbonate, $p$-toluene sulfonic acid, silica gel and sodium sulphate anhydrous were purchased from Systerm Chemical company (Malaysia). Perchloric acid (70\%) was obtained from aserate chemical company (Sydney). Sulfuric acid $(96.7 \%)$ was purchased from J. T. Baker chemical company (USA). Phosphoric acid (98\%) was obtained from BDH chemical company (UK). Filter paper was obtained from whatman (England).

In three necked flask equipped with a reflux condenser $(0.0125 \mathrm{~mol} / 3.6 \mathrm{~g})$ of oleic acid was mixed with $(0.0125 \mathrm{~mol} / 3.53 \mathrm{~g})$ of oleyl alcohol. The reaction mixture was heated on oil bath on a magnetic heater and stirrer until it reach the experiment temperature $\left(90{ }^{\circ} \mathrm{C}\right)$; catalyst $(0.004 \mathrm{~mol} / 0.15 \mathrm{~g})$ sulfuric acid and desiccant $(1.8 \mathrm{~g}$ silica gel) were added to the mixture at that moment.

After completion of the reaction, the flask was allowed to cool to room temperature and the crude product was washed with ethyl acetate ( 3 times $25 \mathrm{~mL}$ ) and filtered to remove the silica gel from the product. The product was transferred into separating funnel and $10 \mathrm{~mL}$ of saturated $\mathrm{NaHCO}_{3}$ solution was then added into the funnel to neutralize the catalytic inorganic acid used in the reaction. Brine (saturated $\mathrm{NaCl}$ ) solution was then added in order to avoid any emulsion formation. 
Extraction was carried out until getting solution with $\mathrm{pH} 7$, the aqueous layer was decanted and the product was dried with sufficient amount of $\mathrm{Na}_{2} \mathrm{SO}_{4}$. The hydrated $\mathrm{Na}_{2} \mathrm{SO}_{4}$ was filtered off. The dried product was then passed through a column packed with silica gel to remove any coloured or decomposed materials formed during the reaction. The columned product was rotary-evaporated to remove the solvent.

Dectection tests for evaporated compound has been done by using fourier transformation infra-red (FTIR), carbon and proton nuclear magnatic resonance $\left({ }^{13} \mathrm{C}\right.$ NMR and ${ }^{1} \mathrm{H}$ NMR) in order to detect the carbonyl group for oleyl oleate

Viscosity index (VI) of the suntheized compound was determined using rheometer with model physical MCR 301 from anton paar instroments company (Germany), while measurements had run on hot plate heater set at $40{ }^{\circ} \mathrm{C}$ and $100{ }^{\circ} \mathrm{C}$. Some physical properties such as pour point (PP), flash point (FP) and viscosity index have been calculated using different procedures ${ }^{17}$.

\section{Results and Discussion}

Figure 1 demonstrate the scheme for the esterification of oleyl oleate reaction. The esterification reaction was carried out with four different kind of homogeneous catalyst such as sulfuric acid, phosphoric acid, $p$-toluene sulfonic acid and perchloric acid at the same reaction conditions. The ester yield \% of every reaction were investigated and compared with each other. Initial esterification conditions were choosen acoording to the study byAksoy et al. ${ }^{18}$ duration, $1 \mathrm{~h}$; temperature, $90{ }^{\circ} \mathrm{C}$; acid/alcohol molar ratio,1:1; type of catalyst, sulfuric acid; amount of catalyst $1.25 \%$ of the weight of the oleic acid; desiccant, silica gel (powder); amount of desiccant, $50 \%$ of the weight of the oleic acid. The comparison of ester yield value is shown in Table 1 . The highest percentage yield was observed in experiment with sulfuric acid because of it increase the reaction rate at the esterification process, which the $\mathrm{H}_{2} \mathrm{SO} 4$ is insensitive to the presence of FAA in the feedstock ${ }^{19}$ the ester yields in the experiment with perchloric acid and phosphoric acid were similar, whereas the yield in the presence of $p$-toluene sulfonic acid higher than with phosphoric and perchloric acid may be due to formation of reagent-catalyst hydrogen bonds ${ }^{20}$.

In the experiments with phosphoric acid, perchloric acid and $p$-toluene sulfonic acid the products where oily, but after a period of time the product had turned into semisolid. This behavior was not observed in the product in which sulfuric acid was catalyst.

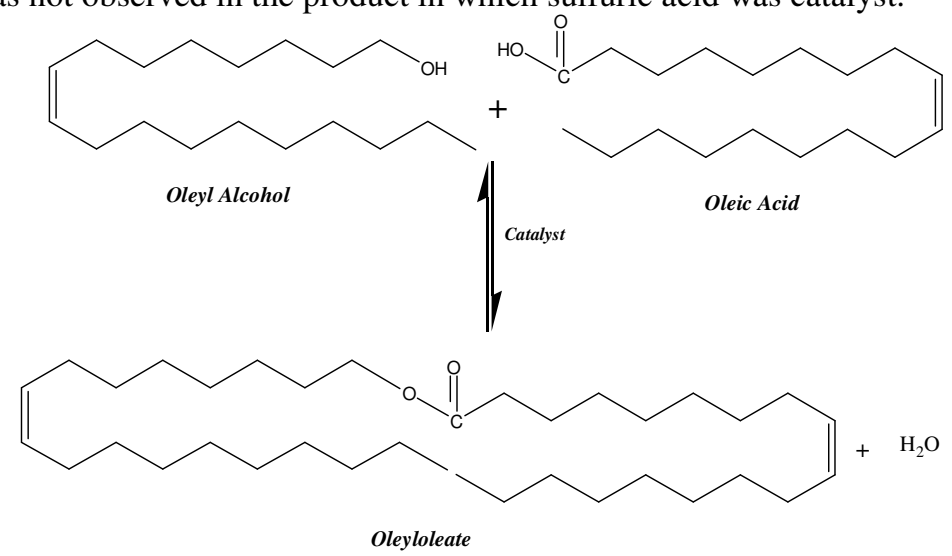

Figure 1. Synthesis of oleyloleate 
Table 1. Comparison of the esterification yields in reactions using various catalysts

\begin{tabular}{ccccc}
\hline Duration & \multicolumn{4}{c}{ Ester yield, \% } \\
\hline \multirow{2}{*}{$2 \mathrm{~h}$} & Sulfuric acid & Phosphoric acid & Perchloric acid & $p$-TSA \\
& 93.88 & 52.7 & 54.9 & 70 \\
\hline
\end{tabular}

The effect of mole ratio of oleic acid: oleyl alcohol and the yield obtained are shown in Figure (2). The highest percentage yield of wax ester achieved was $93.88 \%$ with oleic acid to oleyl alcohol mole ratio of $1: 1$ in $5 \mathrm{~h}$. Furthermore, increase of this mole ratio did not increase in the percentage yield of wax ester. This non-common behavior is due to dissolution vs. kinetics effect. For short times, when the amount of alcohol is high, a dissolution effect of the alcohol over the reaction mixture takes place with a stronger influence than that provided by the kinetics, producing a smaller reaction rate $^{21}$. Furthermore, this result probably due to the hindered the interaction between oleic acid and catalyst with excess alcohol. This was reported earlier by Abdul Rahman et al. ${ }^{22}$.

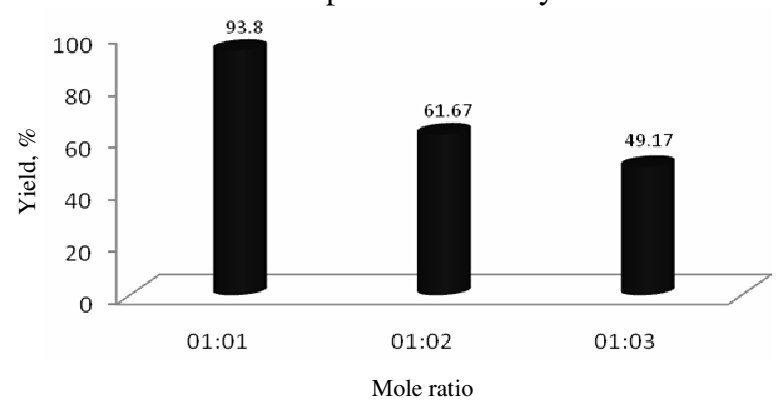

Figure 2. Effect of molar ratio on the esterification reaction of oleic acid and oleyl alcohol

Figure (3). Shows the effect amount of sulfuric acid on the esterification reaction. The percentage yield of wax ester increased with increasing amount of sulfuric acid $0.15 \mathrm{~g}$ to reach maximum value of $93.88 \%$. Nevertheless, when the experiment was repeated with $0.20 \mathrm{~g}$ of sulfuric acid the percentage yield decreased, which this based on equilibrium concept $^{22}$. This phenomenon could be due to the catalyst becoming less active when the extent of hydration increase.

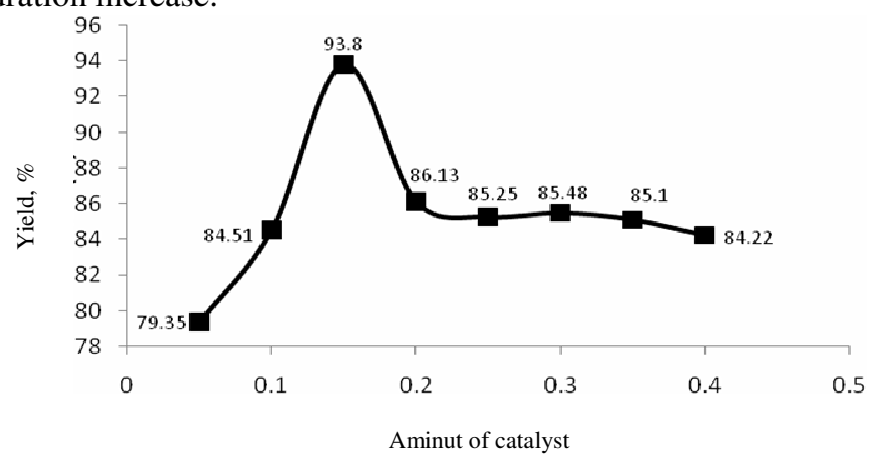

Figure 3. Effect of amount of catalyst on the esterification reaction of oleic acid and oleyl alcohol

The effect of reaction time on oleic acid conversion is shown in Figure (4). Esterification yield increased with increasing the reaction time reaching maximum of $93.88 \%$ in $5 \mathrm{~h}$ at $90{ }^{\circ} \mathrm{C}$, whereas the percentage of yield started to decrease with reaction time $6 \mathrm{~h}$. Finally, the 
ester yield value did not increase when the reaction time was prolonged. This is due to the reaction has achieved the equilibrium state where the rate of forward reaction is equal to the rate of backward reaction, hence the concentration of the product was unchanged ${ }^{23}$.

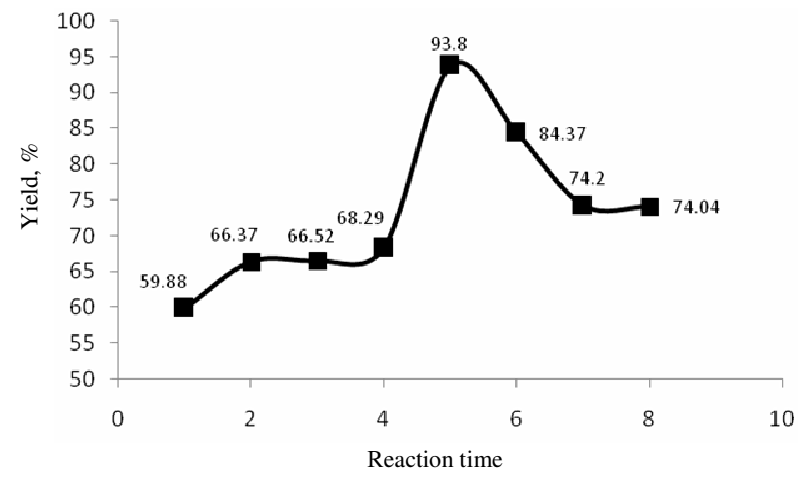

Figure 4. Effect of reaction time on on the esterification reaction of oleic acid and oleyl alcohol

The effect of reaction temperature on the precentage yield of wax ester is shown in Figure 5. The percentage yield increased with arise in temperature, reaching a maximum of $93.80 \%$ in $5 \mathrm{~h}$ at $90{ }^{\circ} \mathrm{C}$. While the reaction was carried out using reaction temperature up to $90{ }^{\circ} \mathrm{C}$, the the percentage yield decreased with reaching a minimum of $74.77 \%$ at $130{ }^{\circ} \mathrm{C}$. Based on the above experiments $90^{\circ} \mathrm{C}$ was found to be the most stable reaction temperature because of the ester percentage yield and consumption of energy ${ }^{24}$. This result corroborate those obtained by (Abdul Rahman \& Aracil et al) ${ }^{22,25}$, which happened due to reduce of the catalyst affectivity by heat at high temperature ${ }^{22}$.

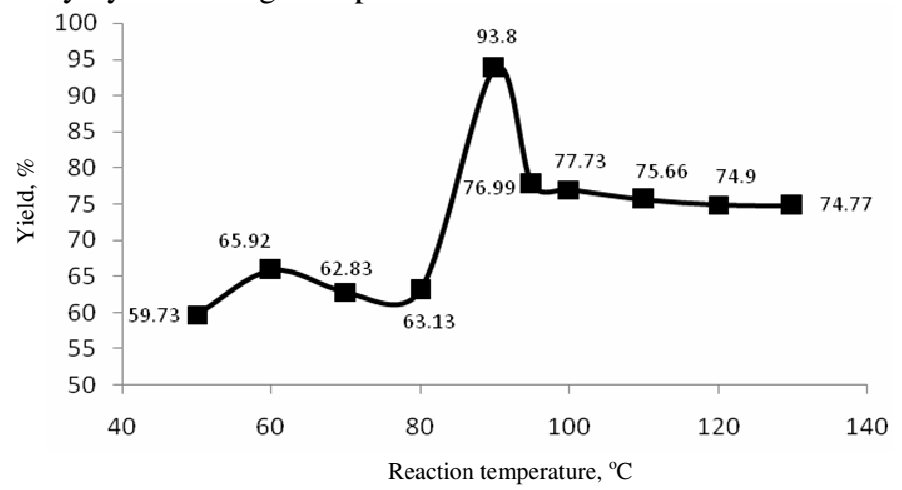

Figure 5. Effect of reaction temperature on the esterification reaction of oleic acid and oleyl alcohol

In order to prove the present of $\mathrm{C}=\mathrm{O}$ of wax ester (oleyl oleate), the final product was tested by FTIR, ${ }^{13} \mathrm{C}$ and ${ }^{1} \mathrm{H}$. The comparison between oleyl alcohol, oleic acid and oleyl oleate FTIR spectra is shown in Figure 6. The date of ${ }^{13} \mathrm{C}-\mathrm{NMR}$ and ${ }^{1} \mathrm{H}-\mathrm{NMR}$ spectra is shown in Table $2 \& 3$. $\mathrm{C}=\mathrm{O}$ group of wax ester can be detected at wave- number $1735-1750 \mathrm{~cm}^{-1}$, while stretching vibration peak of $=\mathrm{CH}$ at $3000-3050 \mathrm{~cm}^{-1}$, stretching vibration peak of free $\mathrm{OH}$ for alcohol can be detected ${ }^{26}$ of wavenumber $3300-3400 \mathrm{~cm}^{-1}$. Based on Figure 6. FTIR spectrum of wax ester show stretching vibration peak at wavenumber $1739 \mathrm{~cm}^{-1}$ attributed to carbonyl stretching frequency of ester moiety. This band combined with two C-O stretching 
bands one stronger and broader than other were occurred in the rang 1172 and $1353 \mathrm{~cm}^{-1}$, respectively. Whereas, the absorption due to $\mathrm{OH}$ of hydroxyl group $3338.38 \mathrm{~cm}^{-1}$ and carbonyl group of carboxylic acid at $1709.87 \mathrm{~cm}^{-1}$ are not observed which confirmed that the esterification reaction was taken place. Based on Table 1 and 2, the presents of $\mathrm{C}=\mathrm{O}$ wax ester can be confirmed by comparison with previous study by Awang et $a .^{27}{ }^{13} \mathrm{C}$ and ${ }^{1} \mathrm{H}$ chemical shift ranges (ppm). ${ }^{13} \mathrm{C}$ chemical shift ranges for unsaturated bond was $100-150 \mathrm{ppm}$, while for $\mathrm{C}-\mathrm{O}$ was $40-80 \mathrm{ppm}$, whereas ${ }^{13} \mathrm{C}$ chemical shift value for $\mathrm{C}=\mathrm{O}$ ester was 155-185 ppm. ${ }^{1} \mathrm{H}$ chemical shift ranges for aliphatic protons, normally at about $1.25-2.53 \mathrm{ppm}$ which would also be shifted down field ${ }^{28}$. However, the methine proton signal was shifted upfield at about 4.60-5.30 ppm which indicates the presence of this type of proton ${ }^{29}$. Furthermore, the most important feature for success of esterification reaction is the presence of the $\mathrm{COOCH}_{2}$ signal at about $4.02 \mathrm{ppm}$.

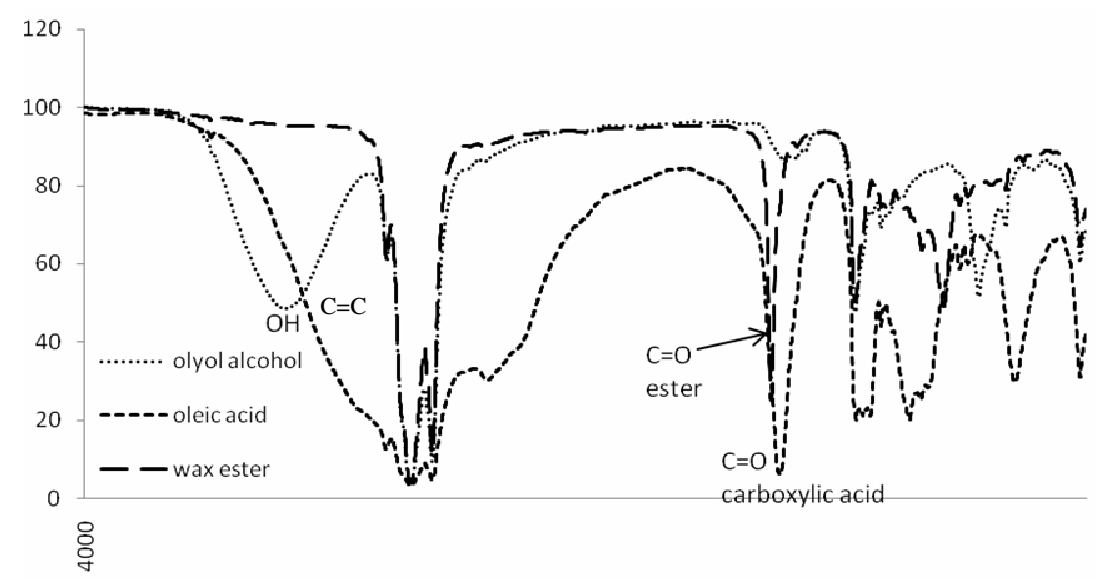

Figure 6. The FTIR spectra of oleyl oleat, oleic acid and oleyl alcohol

Table 2. The main signals present in ${ }^{13} \mathrm{C}$-NMR functional groups of oleyl oleate

\begin{tabular}{ccc}
\hline Assignment & Chemical shifts, ppm & Chemical shift, $\mathrm{ppm}^{27}$ \\
\hline $\mathrm{C}=\mathrm{O}$ & 173.2 & 173.2 \\
$\mathrm{C}=\mathrm{C}$ & 130.6 & 131.0 \\
$\mathrm{C}-\mathrm{O}$ & 64.59 & 65.9 \\
& 32.82 & 33.5 \\
$\mathrm{CH}_{2}-\mathrm{COO}-\mathrm{CH}_{2}$ & $22.76-29.98$ & $22.5-30.1$ \\
$\mathrm{CH}_{3}$ & 14.12 & 14.5 \\
\hline
\end{tabular}

Table 3. The main signals present in ${ }^{1} \mathrm{H}-\mathrm{NMR}$ functional groups of oleyl oleate

\begin{tabular}{ccc}
\hline Assignment & Chemical shifts, ppm & ${\text { Chemical shift, } \mathrm{ppm}^{27}}^{27}$ \\
\hline$-\mathrm{CH}_{2}-\mathrm{COO}$ & 2.26 & 2.25 \\
$-\mathrm{CH}=\mathrm{CH}-$ & 5.32 & 5.43 \\
$\mathrm{CH}_{2}-\mathrm{O}-\mathrm{CO}$ & 4.02 & 4.08 \\
$\mathrm{C}=\mathrm{C}-\mathrm{C}-\mathrm{H}$ & 1.85 & 1.96 \\
$\mathrm{CH}_{2}$ & $1.23-1.33$ & $1.29-1.33$ \\
$\mathrm{CH}_{3}$ & 0.85 & 0.96 \\
\hline
\end{tabular}


Physicochemical properties of prepared compounds are summarized in Table 4. It is known that, as the chain length of the chain ester is increased, corresponding improvement in low temperature behavior was observed. This is due to the greater ability of the longer chain ester which more effectively disrupts crystalline formation at reduced temperature. Therefore, the liquid compound in this study was screened for cold flow performance through the determination of pour point. Another important factor in determining how well oil will behave as a potential biolubricant is to evaluate the oil flash point ${ }^{30}$. The flash point is often used as a descriptive characteristic of oil fuel and it is also used to describe oils that are not normally used as fuels. There are various international standards for defining each, but most agree that oils with a flash point less than 43 are flammable, while those having a flash point above this temperature are combustible ${ }^{31}$. The efficiency of the biolubricant in reducing friction and wear is greatly influenced by its viscosity, the viscosity of oils decreases as temperature increases. If the biolubricant is too viscous, it will require a large amount of energy to move; if is too thin, the surfaces will rub and friction will increase. The viscosity index highlights how a biolubricant's viscosity changes with variations in temperature. The best oils (with the highest VI) will not vary much in viscosity over such a temperature range and therefore will perform well throughout. In this work, increased viscosity index (VI) of the prepared product is the result of its higher molar weight and especially the altered structure of its molecule (Table 4).

Table 4. Physical properties of oleylolate ester

\begin{tabular}{ccccc}
\hline Pour point, ${ }^{\circ} \mathrm{C}$ & Flash point, ${ }^{\circ} \mathrm{C}$ & Vis. @ $40^{\circ} \mathrm{C}(\mathrm{cSt})$ & Vis. @ $100^{\circ} \mathrm{C}(\mathrm{cSt})$ & Vis index \\
\hline-31 & 320 & 17.80 & 5.35 & 197.5 \\
\hline
\end{tabular}

\section{Conclusion}

The sulfuric acid catalyst has been choosen as a higher activity on the esterification of oleic acid with oleyl alcohol. The reaction about $93.88 \%$ under optimal reaction conditions which were determined to be as follow: duration, $5 \mathrm{~h}$; temperature, $90^{\circ} \mathrm{C}$; acid/alcohol molar ratio, $1: 1$; type of catalyst, sulfuric acid; amount of catalyst, $4.1 \%$ of the weight of acid.

\section{Acknowledgment}

The authors acknowledge the Universiti Kebangsaan Malaysia for funding ("Code UKMGUP-NBT-08-27-113" and "UKM-OUP-NBT-29-150/2011") and the direct contributions of the support staff from the School of Chemical Sciences and Food Technology, the Faculty of Science and Technology, Universiti Kebangsaan Malaysia.

\section{References}

1. Goma-Doncescu N and Legoy M D, Am Oil Chem Soc., 1997, 74, 1137-1143.

2. Peter T R and Robert B, Personal Care, 2001, 10, 27-31.

3. Prapulla S G, Karanth N G, Engel K H and Tressel R, J Flavor Fragrance, 1992, 7, 231-234.

4. Langrand G, Trantaphylides C and Baratti J, Biotechnol Lett., 1998, 10(8), 549-554.

5. Chen J P and Wang J B, Enz Microb Technol., 1997, 18, 615-622.

6. Radzi S M, Basri M, Salleh A B, Ariff A, Mohammad R, Abdul Rahman M B and Abdul Rahman R N Z R, Elcctronic J Biotechnol., 2005, 8, 292-298.

7. Liu Y, Lotero E and Goodwin Jr J G, J Cataly, 2006, 242, 278-286.

8. Liu Y, Lotero E and Goodwin Jr J G, J Molecular Catalysis A: Chemical, 2006, 245, 132-140. 
9. Lilja J, Warna J, Salmi T, Pettersson L J, Ahlkvist J, Grenman H, Ronnholm M and Murzin D Yu, Chem Eng J., 2005, 115(1-2), 1-12.

10. Gubicza L, Kabiri-Bader A, Keoves E and Belafi-bako K, J Biotechnol., 2000, 84(2), 193-196.

11. Zhao Z, J Molecular Catalys A: Chemical, 2000, 154(1-2), 131-135.

12. Lilja J, Aumoa J, Sami T, Murzin D Yu, Maki-Arvela P, Sundell M, Ekman K, Peltonen R and Vainio H, Appl Cataly A: General, 2002, 228(1), 253-267.

13. Maeki-Arvela P, Salmi T, Sundell M, Ekman K, Peltonen R and Lehtonen J, Appl Catalysis A:General, 1999, 184, 25-32.

14. Kolah A K, Asthana N S, Vu D T, Lira C T and Miller D J, Ind Eng Chem Res., 2007, 46, 3180-3187.

15. Syamsul K M W, Salina M R, Siti S O and Hanina M N, World Appl Sci J., 2010, 11, 401-407.

16. Saleh A B, Basri M and Razak C N A, Rec Res Dev Oil Chem., 1997, 1, 101-108.

17. Aksoy H A, Kahraman I, Karaosmanoglu F and Civelekoglu H, JAOCS, 1988, 65, 936-938.

18. Kulkarni M G and Dalai A K, Rev Ind Eng Chem Res.,, 2006, 45, 2901-2913.

19. Lacaze-Dufaure C and Mouloungui Z, Appl nCataly A: General, 2000, 204(2), 223-227.

20. Marchetti J M and Errazu A F, Biomass Bioenergy, 2008, 32(9), 892-895.

21. Abdul Rahman M B, Yong K C, Basri M, Abdul Rahman R N Z, Razak C N A and Salleh A B, Malaysian J Chem., 2001, 3(1), 46-50.

22. Chen J P and Wang J B, Enzyme Microb Technol., 1995, 20, 615-622.

23. Ozgullsun A, Karaosmanoglu F and Tuter M, JAOCS, 2000, 77, 105-109.

24. Aracil J, Garcia T and Martinez M, Enzyme Microb Technol., 1993, 15, 607-610.

25. Silvestein R M and Webster F X, Spectrometric identification of organic compounds; $6^{\text {th }}$ Ed., John Wiely \& Sons, Inc.: New York,1998.

26. Awang R, Ghazuli M R and Basri M, Am J Biochem Biotechnol., 2007, 3(3), 163-166.

27. Sharam B K, Adhvaryu Z, Liu Z and Erhan S Z, JAOCS, 2006, 83(2), 129-136.

28. Hwang H S and Erhan S Z, Ind Crops Products, 2005, 23(3), 311-317.

29. Sunitha S, Kanjilal S, Reddy P S and Prasad R B N, Tetrahedron Lett., 2007, 48, 6962-6965.

30. Salimon J, Salih N and Emad Yousif, Asin J Chem., 2010, 22(7), 5468-5476.

31. Salimon J and Salih N and Yousif E, Eur J Lipid Sci Technol., 2010, 112(5), 519-530. 


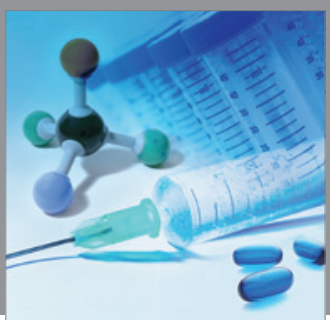

International Journal of

Medicinal Chemistry

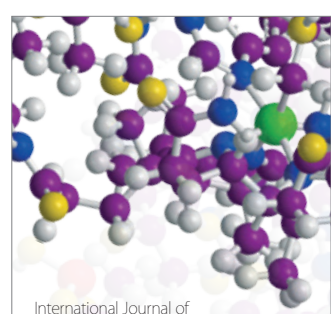

Carbohydrate Chemistry

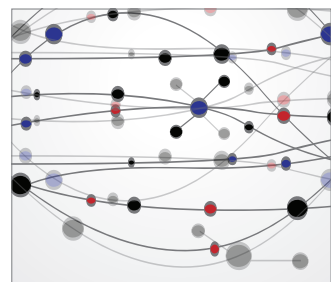

The Scientific World Journal
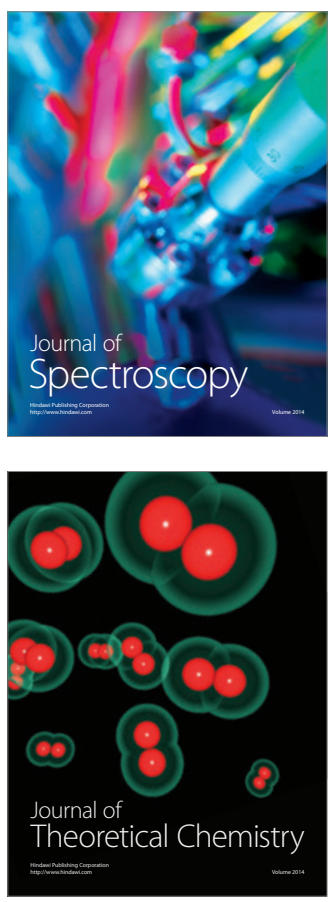
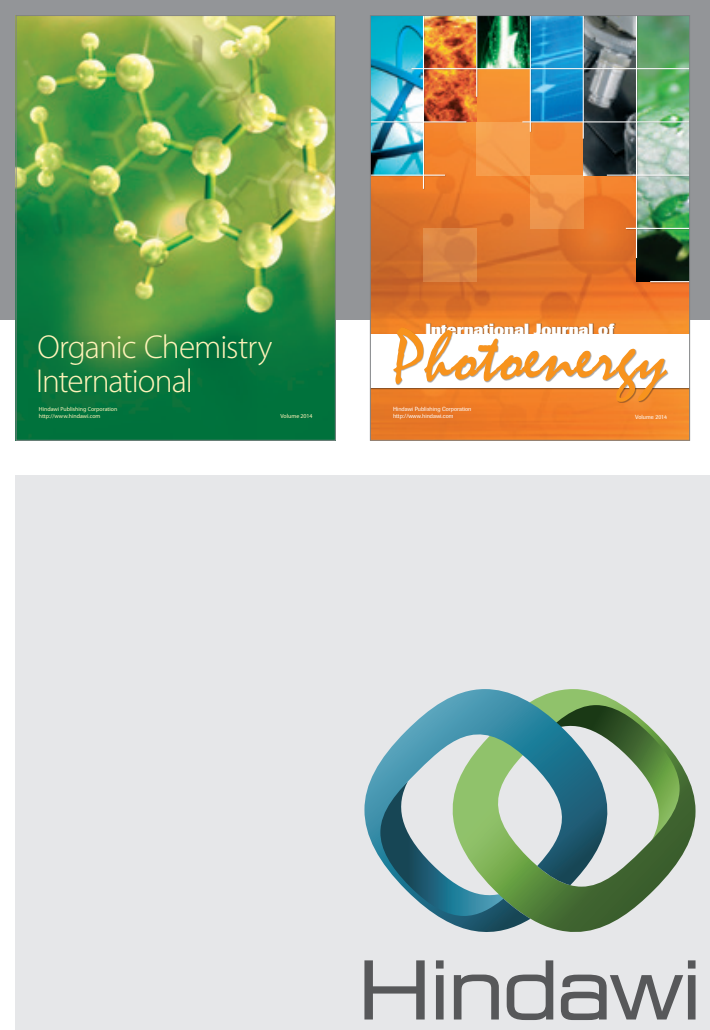

Submit your manuscripts at

http://www.hindawi.com
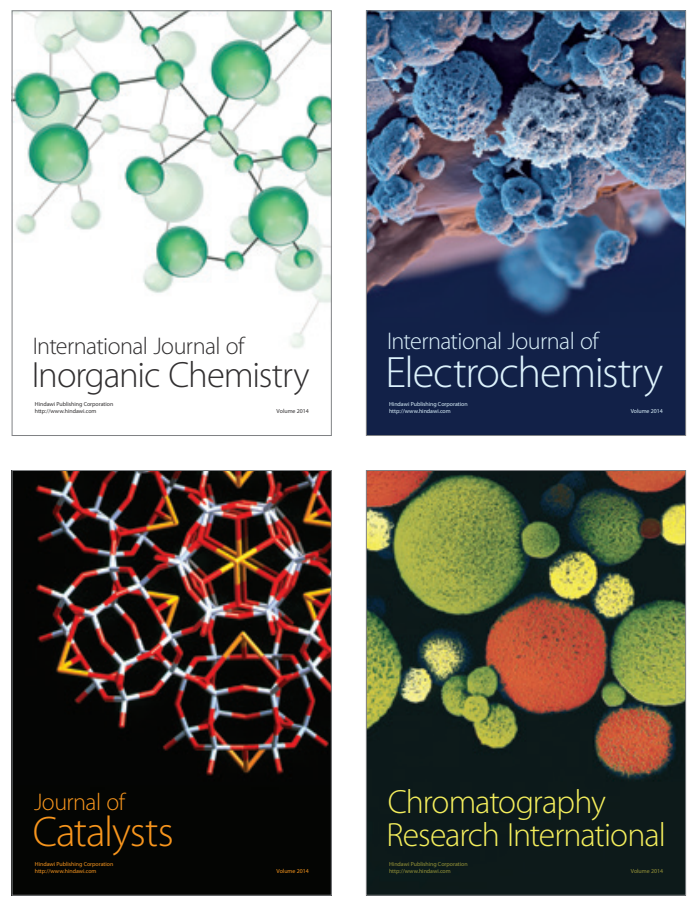
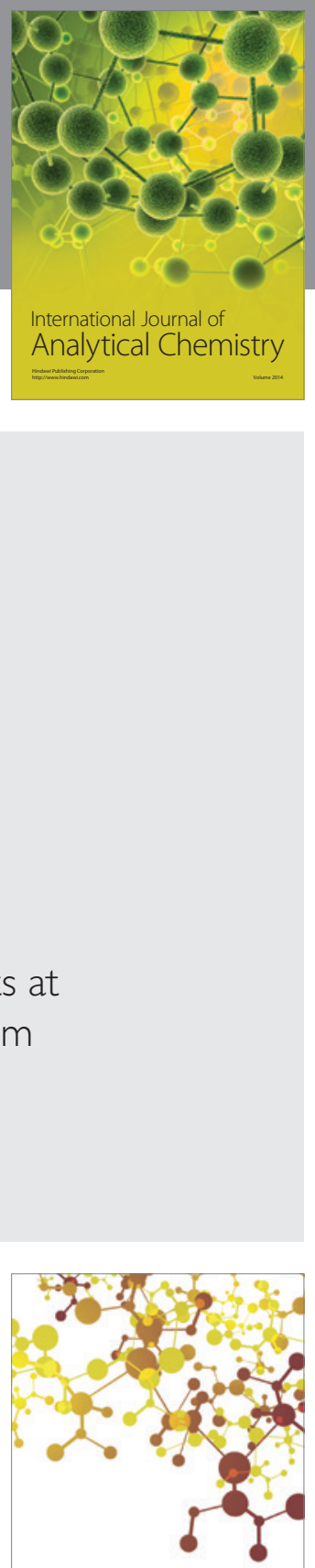

Journal of

Applied Chemistry
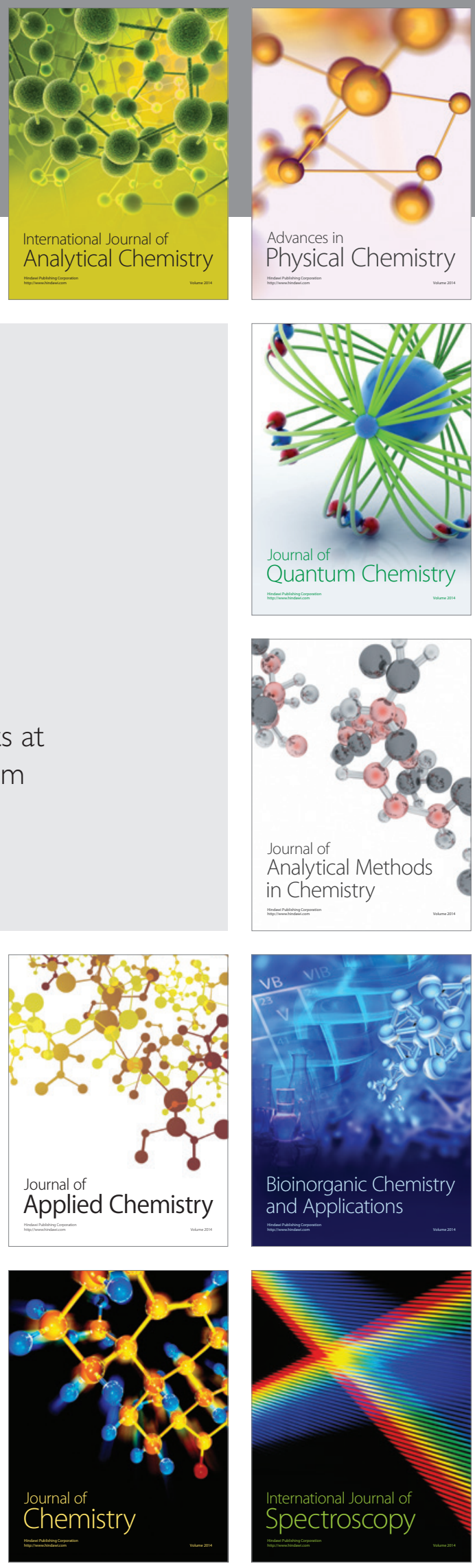